\title{
Teacher-Librarians and ePortfolios: A Perfect Match
}

\author{
Pauline Nicholas and Jennifer Branch-Mueller \\ University of Alberta, Edmonton, Canada
}

\begin{abstract}
This paper introduces the concept of portfolios and ePortfolios and then presents an argument for teacherlibrarians to implement ePortfolios in their schools. Literature about the different types of ePortfolios (process/learning, assessment, showcase/presentation) is summarized and research about integrating ePortfolios in elementary classrooms is shared. A summary of the reasons why teacher-librarians are uniquely qualified and situated for this work is also included.
\end{abstract}

\section{Keywords: Portfolios, Elementary Schools, Teacher-Librarians}

\section{INTRODUCTION}

The teacher-librarian occupies a critical position in the K-12 school system. Building on the notion that the school library is the "hub of the learning community", the teacher-librarian's role becomes central to the successful delivery of the curriculum. The teacher-librarian's cutting edge knowledge and skills in pedagogy, curriculum, and technology are essential in supporting students' learning and fostering lifelong learning. Thus it has become a challenging yet unique responsibility to support learning across content areas and grades.

As traditional pedagogical approaches "come under increased criticism" (Bures, Barclay, Abrami \& Meyer, 2013, p.1), and as the "demands placed on schools today, ... intensified by globalization, declining resources, greater calls for accountability, and the impact of information technology" (Brown \& Bruce, 1997, p.201), it is not by coincidence that the approaches to teaching and learning are constantly changing. Educators, including teacher-librarians, are challenged to modify their teaching and learning strategies, and the school library must incorporate new programs to reflect and meet the changing needs of the society and the school community. e-Portfolios, one of the latest innovative educational strategies and tools, are gradually gaining grounds in K-12 classrooms. It is important for students to know the content of each subject and be able to apply knowledge and skills solve real world problems. ePortfolios, as a process and product, can used to enhance learning and assessment at all levels and across all subjects. Thereby ideally complementing the role of the teacher librarian as an educator and information specialist.

\section{PORTFOLIOS}

"The word portfolio is derived from the Latin words portare meaning to carry; and foglio, meaning sheet of paper" (Vermilion, 2008, p. 67). In the early beginnings, a portfolio was used mainly to represent a container or "portable case" (Bryant \& Chittum, 2013) of samples of work from professionals in fields such as fine arts, music writing and architecture who are seeking employment. The works in the portfolio showcase the talents and capabilities of the applicants and the prospective employers are able to formulate an accurate persona of the owner of the portfolio.

The purposes and principles underlying the integration of portfolios in classrooms are no different. According to Eby, Herrell and Jordan (2006), at the K-12 level, students select diverse samples of their work based on goals agreed on between the teacher and the student, and these works are showcased and presented for assessment in folders. The folders with the individual student's name written are usually stored in well labelled, sometimes colored boxes until they are needed. A single folder not only hosts the finished products but drafts and revisions of assignment and projects are included. Eby, Herrell and Jordan (2006) further noted that through various programmes such as portfolio days, students 
celebrate their work. Eby, Herrell and Jordan (2006) also explained that each sample provides statements that explain why the work was included in the portfolio. By reflecting on the process and the end product an accurate evaluation of the student's growth and development over the period may be made.

Additionally, the student's develop their "metacognitive abilities that can be applied to future selfassessment in academic or real-life settings' (Eby, Herrell \& Jordan, 2006, p. 279).

\section{EPORTFOLIOS}

The shift from binders to the online environment creates portfolios that are more flexible, scalable and dynamic (Bryant, \& Chittum, 2013). The owners add, share, and alter their work more easily. Whereas the Texas Education Agency (2013) described an ePortfolio as a curated collection of digital artifacts representing hard work, creativity and collaboration; Barrett (2007) elaborated:

An electronic portfolio uses electronic technologies as the container, allowing students/teachers to collect and organize portfolio artifacts in many media types (audio, video, graphics, text); and using hypertext links to organize the material, connecting evidence to appropriate outcomes, goals or standards .... It is a collection of work that a learner has selected, organized, reflected upon, and presented to show understanding and growth overtime. (p. 436)

The educational ePortfolio has it roots in universities and colleges, but it is "gradually working its way in the lower grades" (Vermilion, 2008, p. 67), cutting across all disciplines and grades. In practice, eportfolios are used by teachers and teacher-librarians to demonstrate learning, showcase the students capabilities, and enhance the assessment process. "As a technological innovation rather than conceptual", the major uses are to: a) plan educational programs, b) find a job, c) evaluate a course, d) monitor and evaluate performance e) document knowledge, skills, abilities, and learning; f) track development within a program (Aygün \& Aydin, 2016, p. 208). A key difference between the traditional portfolio and the digital version is that the traditional portfolio mantra of collecting, selecting, reflecting, projecting, and celebrating is now leveraged by technology to include archiving, linking/thinking, storytelling, collaborating and publishing (Barrett, 2005). Importantly, it tracks learning by providing authentic evidence.

An ePortfolio is about authentic learning and assessment. Thus its integration in teaching and learning is based on sound theoretical foundations ideal for 21 st century classrooms. According to Barrett (2007), although K-12 learning places greater emphasis on ePortfolios that are for showcase purposes (highlighting competencies of students), there are also examples of their use for assessment and learning. It must be noted that the uses are more often interconnected and overlapped. The assessment ePortfolio model is more aligned to the positivist paradigm where the "student's attainment is documented based on predetermined, external standards and meaning is constant across users, contexts, and purposes" (Nicolaidou, 2013, p. 405). The learning ePortfolio model is associated with the constructivist paradigm and is context determined and "assumes that meaning varies across individuals, over time, and with a purpose" (Nicolaidou, 2013, p. 405). Barrett (2007) noted that the artifacts of the learning ePortfolio tell stories about the student's learning process and development and, therefore, the same artifact may have different meanings to different students.

The learning eportfolio emphasizes a student-centered approach instead of a teacher-centered one. When students are in actively involved in their learning, the locus of control is shifted from the teacher to the students, thereby giving the students greater autonomy. Since it is argued that students learn by doing (Lombardi, 2007), by actively involving in their learning, and gaining experiences solving real-life problems (Har, 2013) creating an ePortfolio is an effective educational strategy that fosters deep engagement on the part of the student. However, Barrett (2016) advised that students in lower grades will need greater attention and more scaffolding since it can be difficult for students below $3^{\text {rd }}$ grade to take responsibility for their learning. In spaces where the curation of artifacts is done mainly by the teacher, the learning process becomes more teacher-centered. This may be unavoidable at the lower levels but the teacher then should find the balance. 
Additionally, there are theoretical arguments that ePortfolios improve reflection (a higher order skill) and learning outcomes as well as increased integration of knowledge, and self-regulated learning (Bures, Barclay, Abrami, \& Meyer, 2013; Nicolaidou, 2013). "When students incorporate artifacts from multiple disciplines and are asked to synthesize and reflect on them", an ePortfolio become a means of constructing knowledge and developing core skills (Bryant \& Chittum, 2013, p. 190) such as reflection and metacognition. Finally, at the elementary level, ePortfolio creation enables students to demonstrate both more traditional literacy skills as well as new literacy skills as they incorporate and blend diverse artifacts from text to visual, auditory and multimedia (Bures, Barclay, Abrami, \& Meyer, 2013).

\section{ePorfolios in K-12}

While literature on ePortfolios as a learning tool is growing and is finding a place in $\mathrm{K}-12$ classrooms, published empirical studies are still limited (Barrett, 2005; Bryant \& Chittum, 2013). And yet those available are generally based on practice at the postsecondary level (Bryant \& Chittum, 2013), and less emphasis is placed on its application in the K-12 education. The assumption is that students at the elementary level lack the requisite literacy skills including computer skills (Lin, Yang, Hung \& Wang, 2006; Saarinen, Seitamaa, \& Hakkarainen, 2016; Texas Education Agency, 2013). Interestingly, these students who are born in the digital age and may have technology at their 'finger-tips' often face challenges when the technology is to be used in educational settings. However, new ePortfolio programs and web-based tools can make ePortfolio creation easier than ever.

In a comprehensive review of literature done by Saarinen, Seitamaa-Hakkarainen, and Hakkarainen (2016) covering the period 1996 to 2012, only 49\% of the total articles located presented original data on the use of ePortfolios. Then, of the $49 \%$ of empirical studies identified, $69 \%$ were affective describing participants feelings and opinions about ePortfolios, and $31 \%$ were about students outcomes. Additionally, $42 \%$ were more descriptive or practice oriented. Another $10 \%$ were technological, addressing issues of models, platforms and usability. Although, there was no data indicating the educational levels, a gap exist regarding empirical research on the use of ePortfolio at the K-12 level was evident.

The Myportfolio initiative in New Zealand under the auspices of the Ministry of Education is an exemplar of an outstanding ePortfolio project at the elementary level. Munroe (2011) explained that at no cost to the individual schools, elementary students and teachers from across New Zealand have the opportunity to benefit from the scalability and flexibility of ePortfolios in learning. Using the 'MyPortfolio' platform, students and teachers create electronic portfolios for various uses, receive feedback on them, engage in discussions, build group ePortfolios and share files. Social media functionalities allow the users to connect with each other, form communities, and publish the content they have created. Importantly, evidence of students learning is gathered easily and effectively, validated by the teachers, and showcased when necessary. Parents can also view their children's learning trajectory.

In order to determine the teachers' perceptions of the project, Munroe (2011) interviewed eleven teachers from different schools in New Zealand that implemented ePortfolios. The results indicated that all 11 teachers valued the use of ePortfolios and inferred that it was beneficial to the students. In addition, all but one confirmed a willingness to use ePortfolios as a learning tool if they were to move to another school.

\section{Process or Learning ePortfolios}

Zubizarreta argued that the primary motive of a learning ePortfolio is "to improve student's learning by providing a structure for students to reflect systematically over time on the learning process, and to develop the aptitudes, skills and habits that come from critical reflection" (as cited in Barrett, 2007, p. 438). Critical actions within a learning ePortfolio include observation of students' progress, setting of goals, receiving feedback and making changes based on the feedback, reflection on the process, and selfand peer-evaluation. These actions generate deep learning and create new knowledge.

Nicolaidou (2013) engaged in a study with 4th graders at the Cyprus Primary School to determine if a process ePortfolio can positively affect students' writing performance. The students created an ePortfolio in a Language Arts class to demonstrate their ability to write a structured and well-organized 
essay that, among other things, is cohesive, grammatically correct, and free from spelling and punctuation errors. Through a mixed method case study, the 20 students who participated in the study were evaluated at the end of a one year period. The results indicated that the students valued feedback from their peers (formative assessment). Another important finding indicated that an ePortfolio can support the development of primary students' writing performance and peer feedback skills in essay writing. An ePortfolio "supports a more authentic process of writing as students go through a process of revising draft versions, reflecting on them, and finally publishing or finalizing work" (Bures, Barclay, Abrami, \& Meyer, 2013, p. 3).

Although responses from the teachers in the same study were also positive, the findings indicated that low-ability students did not benefit as much as average and high-ability students. According to Nicolaidou (2013), low-ability students lacked the necessary skills to make the suggested changes based on comments from peers and teachers. And they also lacked the ability to make valuable comments on their peers' ePortfolios. In light of the fact that there are inherent features and functionalities for individualized learning, teachers should provide these students with more support and guidance.

Saarinen, Seitamaa-Hakkarainen, and Hakkarainen (2016) examined students' experiences using ePortfolios in craft education over a three year period in a Finnish school context. As a support for learning and assessment tool, ePortfolios were used not only to demonstrate samples of the working processes and advancement of the students' understanding but also their strengths and weaknesses. Included in the students' ePortfolios were artifacts in the form of photos, and text that explained and described the artifacts, and the students' progress and feelings while creating the ePortfolio. The ePortfolios were evaluated, and contributed to the students final assessment at the end of the year.

The findings from the study indicated a $100 \%$ satisfaction with the educational value of ePortfolios especially in relation to support for memory and retention. Students were satisfied "with the method of collection of authentic evidence of their own learning process and were confident in their own abilities to work with ICT" (Saarinen, Seitamaa-Hakkarainen, \& Hakkarainen, 2016, p. 36). By incorporating feedback, young students may be motivated to be better writers but teachers will have to be prepared for the long haul since the process of creating eportfolio is time consuming (Aygün \& Aydin, 2016; Bures, Barclay, Abrami, \& Meyer, 2013).

\section{Assessment ePortfolios}

Most standardized tests especially when using multiple choice questions, have proven inadequate in educational assessment. "Thus ePortfolio assessment is a viable alternative assessment that follows the constructivist theory to support meaningful learning" (Lin, Yang, Hung, \& Wang, 2006) by allowing for more contextualized learning and differentiation (Bures, Barclay, Abrami, \& Meyer, 2013), and replication of real world challenges (Mueller, 2005).

Barrett $(2005 ; 2007)$ differentiated between two types of assessment - assessment for learning, and assessment $\boldsymbol{o f}$ learning. ePortfolios that focus on assessment for learning tasks are closely linked to formative assessment that tracks students' development over a period of time. On the other hand, ePortfolios used as assessment $\boldsymbol{o} \boldsymbol{f}$ learning are evaluative or summative ePortfolios (Barrett $(2005 ; 2007)$. Assessment for learning or formative assessment is the "process of seeking and interpreting evidence for use by learners and their teachers to decide where learners are in their learning, where they need to go, and how best to get there" (Barrett, 2005, p. 16). Both self- and peer-assessment have become a central component to formative assessment. Authentic assessment can be a short assignment or task. What is important is the fact that the task captures the meaning and application of the knowledge in real a setting. In addition to knowing the content, the student should be able to use the knowledge in authentic tasks to construct meaning.

Lin, Yang, Hung, and Wang (2006) examined the application of ePortfolio in visual-art education as a part of the reform process of compulsory education in the Grades 1-9 curriculum in Taiwan. The appreciation of ePortfolio and its use as an assessment tool among $5^{\text {th }}$ grade visual arts students at the TaiJiao primary school in Taipei, Taiwan was investigated. Peers were required to make comments on paintings that were skillfully and creatively created by other students, digitized using either a scanner or digital camera, and stored in an online portfolio. The responses from a questionnaire regarding their 
understanding and views on peer assessment, indicated that although the students did not like peerassessment, they concurred that the strategy improved learning and that it was more effective than the traditional forms of assessment such as multiple-choice examinations. "The students think that peer assessment influences their learning attitude" (Lin, Yang, Hung \& Wang, 2006, p. 9). They were motivated to pay attention in class because they knew their peers would be critiquing the artifacts in their ePortfolio. Another component of formative assessment is self-assessment. Black \& Williams (1998) emphasized that self-assessment is an essential component when anyone is trying to learn, feedback about the effort has three components: recognition of the desired goal, evidence about present position, and some understanding of a way to close the gap between the two" (p. 6). Achievement standards are raised when teachers and students undertake formative assessment on what has been learned in order to make "high stake decisions" (Barrett, 2005, p. 18).

\section{Showcase or Presentation ePortfolios}

A showcase ePortfolio focuses on final accomplishments or products (Nicolaidou, 2013). Students show examples of their work and achievement rather than telling about them. ePortfolios empower students to create and own their identities, showcase their accomplishments, and make excellent first impression. Students may determine their future by "putting their best digital footprint forward" (Husid \& Wallace, 2015, p. 40). According to Cooper (2016), "not only should students be learning how to do their work, they should be learning and experiencing how to share and market their creations", and the online environment provides an excellent space to have this done creatively ("Teaching Entrepreneurialism" para. 1). This view is supported by the Texas Education Agency (2013) who purport that by showcasing students' exemplary works, the ePortfolio in K-12 "can follow the student whether the move is between courses, grades levels, campuses, districts, higher learning institutions, or career" (p. 8). A learning ePortfolio more often serves as a tool for assessment and a showcase of best works.

\section{TEACHER-LIBRARIANS AND EPORTFOLIOS}

When students were asked by the Association for Supervision and Curriculum Development (ASCD, 2008) what they wanted from their teachers, They stated that their teacher should:

Take me seriously

Challenge me to think

Nurture my self-respect

Show me I can make a difference

Let me do it my way

Point me toward my goals

Make me feel important

Build on my interests

Tap my creativity

Bring out my best self (ASCD, 2008, p. 1)

If the above expectations stand true, then the teacher-librarian in the $21^{\text {st }}$ century school library also has a transformational and multifaceted role. The American Library Association (n.d.) states that:

School library media specialists [teacher-librarians] are an integral part of the total educational team which prepares students to become responsible citizens in a changing global society. In today's information age, an individual's success, even existence, depends largely on the ability to access, evaluate and utilize information. Library media specialists are leaders in carrying out the school's instructional program through their separate but overlapping roles of information specialist, teacher and instructional consultant. (para.1)

Brown and Bruce (1997) used the concept 'mirror-image plus' to further expound on the role of the teacher-librarian. "Reacher-librarians must be mirror images of other teacher leaders, while also bringing added value as leaders in teacher-librarianship" (Brown \& Bruce, 1997, p. 200). As a qualified teacher with professional training in librarianship, an effective teacher-librarian is able to draw on his/her expertise as a teacher and a specialist in library and information science to solve educational problem. 
According to the Alberta Teachers' Association (1993), opportunities for learning will increase and students learning outcomes strengthened if a teacher-librarian is involved in the instructional program of the school.

\section{Long-term Connections with Students}

With knowledge and skills in pedagogy, the teacher librarian interacts with the students every year. The teacher-librarian through the dual role as a teacher and information specialist takes on a more active role as teacher and instructor engaged in curriculum development (Asselin, 2001) as well as collaborative teaching and information literacy instruction (Branch, \& Oberg, 2001; Brown, \& Bruce, 1997; Church, 2008; Scheirer, 2000). Instruction should be flexible and responsive to the needs and interests of each child and at the same time improve student learning.

In a study done by Church (2008) that sought to ascertained principals perception of the role of teacher librarians, $94.6 \%$ either agreed or strongly agreed that teacher-librarians should teach information literacy skills to all students, and $91.8 \%$ sanctioned a collaborative approach. The teacher-librarian, with knowledge of effective $21^{\text {st }}$ century learning strategies, incorporates the appropriate and relevant strategies, including using Information and Communication Technologies (ICTs) to optimize student learning. Information literacy skills should be integrated in lessons across grades and subjects based on the mandates of the curriculum. This makes the teacher-librarian the only member of the instructional team who has the opportunity to interact with all the students in formal teaching and learning sessions throughout any given academic year. This role situates the teacher-librarian in a central position to support the implementation of ePortfolios in a school.

\section{Leadership in Authentic Assessment}

Assessment is the twin of instruction. Teaching is usually followed by assessment to determine if learning has taken place and to what extent. However, the inability of current assessment procedures to assess the full range of essential student learning outcomes, and for teachers to be able to use the information gained for instructional planning, have influenced the consideration for an alternative means of assessment that is more authentic (Callison, 1998). "Research shows that if pupils are given only marks and grades they will not benefit from feedback" (Black \& Williams, 1998, p. 8). In a time when accountability to government and other stakeholders has high stakes, alternative methods that reflect how effectively students can apply knowledge in real world context is an imperative. Mueller (2005) suggested that one can only infer from multiple choice questions that a student has acquired the knowledge and skills required based on standards; however the only way to know if the student is able to apply these in a real world situation is to provide authentic assessment.

According to Callison (1998) authentic assessment is an evaluation process that involves multiple forms of performance measurement reflecting the student's learning, achievement, motivation, and attitudes, on instructionally-relevant activities. Mueller (2005) made the case for this form of assessment in the teaching of information literacy since the traditional forms limits the type and quality of information produced. Authentic representations of classroom daily activities, social interactions, use of multiple resources or real life situations are not captured in multiple choice tests (Callison, 1998). The teacher-librarian has a role to play in creating an assessment culture that relies on new understandings of learning and evidence (Thomas, Chow, \& Franklyn, 2011). Having knowledge and skills in various types of assessment, the teacher-librarian is in a position to help teachers shift from textbook and multiplechoice exams to alternative techniques such as "performance assessment, portfolios and self-assessment" (Callison, 1998, para. 1).

\section{Leadership in Technology Integration and Support}

With the proliferation of technology, there has been an increase in the integration of technology into the curriculum. And the teacher-librarian should be at the helm of "weaving such skills throughout the school community, so that all members of the school community are effective users of ideas and information" (AASL as cited in Johnston, 2015, p. 17) for the purpose of learning. While there are some schools with staff directly responsible for technology, other schools are not as fortunate. In schools with an information technology (IT) person, the teacher-librarian is often required to provide technology 
support by working as a partner. In the case where there is no IT staff, the teacher-librarian fills the gap as the key person, or the go-to person for any issue regarding technology. Johnston (2015) noted that the American Library Association task the teacher-librarian as the person with overall responsibility for the management of technology and the infusion of technology in the curriculum. It is expected that the teacher-librarian works collaboratively with the teachers, students, and the technology specialist to this end. "The teacher-librarian serve as an enabler when there is collaborative relationship and as a barrier when the relationship is competitive" (Johnston, 2015, p. 18). As an information specialist, the teacherlibrarian should have an understanding of how technology can and should be used appropriately in the classrooms.

\section{Leadership in Research and Inquiry Projects}

In many schools the teaching of the complex skills of the inquiry process and research strategies rest with the teacher-librarian. Alberta Learning (2003) stated that:

Inquiry-based learning is a process where students are involved in their learning, formulate questions, investigate widely and then build new understandings, meanings and knowledge. That knowledge is new to the students and may be used to answer a question, to develop a solution or to support a position or point of view. The knowledge is usually presented to others and may result in some sort of action. (p. 1)

The teacher-librarian is uniquely positioned to support inquiry and we know that these skills are of paramount importance in the information age when students face information overload especially as they use the Internet. Understanding how to conduct a research or inquiry project leverages opportunities for students to become not only information literate but critical thinkers, and independent, lifelong learners.

Mancall, Aaron, \& Walker (1986) expressed that a critical thinker has the ability to assess the authenticity and accuracy of information and that these are demonstrated when an individual is able to:

distinguish between verifiable facts and value claims

determine the reliability of a source;

determine the factual accuracy of a statement

distinguish relevant from irrelevant information, claims or reasons

detect bias

identify unstated assumptions;

identify ambiguous or equivocal claims or arguments;

recognize logical inconsistencies or fallacies in a line of reasoning;

distinguish between warranted or unwarranted claims; and

determine the strength of an argument. ("Critical Thinking" para. 2)

The models used to achieve these discrete skills among K-12 students and that keep recurring in literature include Kuhlthau's Information Search Process (1985; 1989); Eisenberg and Berkowitz's the Big6 (1988); Stripling and Pitts's research process model (1988); McKenzie's research cycle (2000); and the Alberta Inquiry model (Alberta Learning, 2003). Despite the varied models, their sole purpose is to ensure that students become information literate. That is, students need to be able to identify when there is a problem to be solved, be able to locate and select the appropriate information to solve the problem, and then use that information effectively to solve the problem and/or make decisions. Through a systematic approach to the development of these skills, the teacher-librarian makes sure that students understand that the skills that are being taught are transferable to other learning situations (Branch, 2003, p. 6).

\section{Meta-cognition Skills}

Metacognition or 'thinking about thinking' is a fundamental underpinning of the teaching of information literacy skills and lifelong learning. However, Spruce and Garrison (n.d) suggest academic achievement requires more than having students thinking about their thoughts; the ability to plan, monitor, and reflect upon a learning event is metacognition and/or self-regulated learning. They asserted that one important factor of academic success is a student's ability to monitor his or her own learning 
(Spruce \& Garrison, n.d.). It is an imperative that teacher-librarians define and articulate their role in the teaching of metacognitive skills (Mancall, Aaron, \& Walker, 1986). Students metacognitive skills may be improved by engaging students in authentic activities, and by deliberately and consciously infusing tasks that require self-assessment, making choices, reflecting, evaluating, and monitoring learning (Lombardi, 2007). Reflection, according to Milam (2008) is a "powerful strategy for constructing knowledge and improving retention of information (p. 285). When students reflect on their learning, Milam (2008) noted, they carefully and seriously consider what they have gained from the activity.

The teacher-librarian's role is critical in helping students recognize their strengths and weaknesses and determining useful strategies to help overcome these weaknesses and build on strengths (Spruce, \& Garrison, n.d.). The fluidity of the present job market and the infusion of technology in the work processes are just a few of the reasons why we need to help build these skills in students from a very early age. The development and fostering of these skills in students should not be left to chance; students should be taught by infusing them into the curriculum. And using learning ePortfolios as a way to build these skills over time seems like a natural fit for the teacher-librarian.

\section{CONCLUSION}

The role of teacher-librarians includes leadership in instruction, research and inquiry, and technology integration. Importantly, students expect that teachers challenge them to think and bring out the best in them. In performing these roles efficiently, the teacher-librarian works with students across grades and subjects throughout the year, draw on their cutting-edge pedagogical and technological skills and knowledge. Since ePortfolios have the ability to document students' learning over time and across grades and subjects, it is a perfect tool and strategy that complements the role of the teacher-librarian. Husid \& Wallace (2015) confirmed the pivotal role of the teacher librarian in its creation and implementation in schools. By virtue of teacher-librarian's inherent emphasis "on information literacy: knowing why information is important, when to research it, how to preserve it and when to use it", the teaching of ePortfolio creation should be a collaborative effort (Husid \& Wallace, 2015, p. 40). In so doing, students benefit from the collaboration between a teacher-librarian, classroom teachers, and information technology staff (if present in school) to infuse ePortfolios into the curriculum. By increasing student engagement, embracing active learning, and fostering authentic learning and assessment, ePortfolios take a student-centered approach where students learn by doing, and new knowledge is created. In an era where the role of the teacher-librarian and their impact on teaching and learning often comes under scrutiny, taking the lead on ePortfolio development and support may be just the thing to help administration, teacher, and parents understand the vital role of teacher-librarians in schools. 